\title{
First-line treatment for chronic myeloid leukemia: dasatinib, nilotinib, or imatinib
}

\author{
Guoqing Wei ${ }^{1,2}$, Shamudheen Rafiyath², Delong Liu²
}

\begin{abstract}
Imatinib, a tyrosine kinase inhibitor (TKI) of BCR-ABL, was the standard first-line therapy for chronic myeloid leukemia (CML) for almost 10 years. Dasatinib and nilotinib, two newer drugs with higher potency than imatinib against $B C R-A B L$ and activity against most imatinib-resistant BCR-ABL mutations, have each shown superior efficacy compared with imatinib for first-line treatment of chronic-phase CML in randomized phase 3 trials. With 14 months follow-up time, available data suggest no obvious differences in efficacy between dasatinib and nilotinib. Compared with imatinib, dasatinib is associated with higher rates of pleural effusion and thrombocytopenia, but lower rates of edema, gastrointestinal AEs, musculoskeletal AEs, and rash. Nilotinib is associated with higher rates of dermatologic toxicity, headache, and biochemical abnormalities associated with hepatic and pancreatic toxicity compared with imatinib, but lower rates of edema, gastrointestinal AEs, muscle spasm, and neutropenia. Several studies have shown that poor adherence to imatinib detrimentally affects responses and should be considered in patients with a suboptimal response. The different dosing requirements of dasatinib (once daily with or without food) and nilotinib (twice daily with fasting) may be an additional factor in selecting frontline agents. This review compares and contrasts the three FDA approved first line TKI agents.
\end{abstract}

\section{Introduction}

Imatinib, which inhibits the tyrosine kinase activity of $\mathrm{BCR}-\mathrm{ABL}$, was introduced as a first-line treatment for chronic myeloid leukemia (CML) almost 10 years ago and radically improved the outcome of patients with CML. Imatinib has been the standard therapy for CML due to its remarkable activity and mild toxicity. In the IRIS study (International randomized study of interferon vs STI571) of first-line treatment with imatinib or interferon and cytarabine in patients with newly diagnosed chronic phase (CP)-CML, patients in the imatinib arm had an 8-year overall survival rate of $85 \%$ and freedom from progression to advanced disease was 92\% [1]. Imatinib was also generally well tolerated during long-term treatment.

Despite the responses observed with imatinib, a proportion of patients develops resistance to imatinib or cannot tolerate its side effects. This led to the development of newer tyrosine kinase inhibitors (TKIs) of BCR-ABL, including dasatinib, nilotinib, and bosutinib, that were

\footnotetext{
* Correspondence: delong_liu@nymc.edu

${ }^{2}$ Division of Hematology and Oncology, New York Medical College and

Westchester Medical Center, Valhalla, NY 10595, USA

Full list of author information is available at the end of the article
}

initially tested in clinical studies of patients with prior imatinib therapy [2-5]. Dasatinib, nilotinib and bosutinib, respectively, have 325-fold, 20-30-fold, and 30-fold increased potency over imatinib against BCR-ABL kinase in vitro [6-9]. Nilotinib has a similar chemical structure to imatinib but has an improved topographical fit in the ABL kinase pocket $[6,7,9]$. Dasatinib has a completely different chemical structure to imatinib and, unlike imatinib and nilotinib, binds BCR-ABL in the active conformation $[10,11]$. Bosutinib binds to an intermediate form of BCRABL [8]. All three TKIs have activity against most of the mutated forms of BCR-ABL kinase that have been associated with clinical resistance to imatinib [6,9]. Dasatinib $100 \mathrm{mg}$ once daily (QD) and nilotinib $400 \mathrm{mg}$ twice daily (BID) have been approved in the US and Europe as treatments for patients with CML who are resistant or intolerant to imatinib (dasatinib for all phases of CML, nilotinib for CP and accelerated phase [AP]). Dasatinib $100 \mathrm{mg}$ QD and nilotinib $300 \mathrm{mg}$ BID were recently approved in the US for patients with newly diagnosed CP-CML. Bosutinib is still undergoing clinical trials.

Clinical trials assessing the newer TKIs (dasatinib, nilotinib, and bosutinib) as first-line therapies in newly diagnosed CP-CML are ongoing and results from trials of 
dasatinib and nilotinib have recently been reported. For dasatinib, published clinical trials in newly diagnosed CPCML comprise: (i) DASISION (Dasatinib versus imatinib study in treatment-naive CML patients), an international, multicenter, randomized phase 3 trial of dasatinib 100 mg QD vs imatinib $400 \mathrm{mg}$ QD $(\mathrm{n}=519)$ [12]; and (ii) a single-arm phase 2 trial of dasatinib $100 \mathrm{mg}$ QD or $50 \mathrm{mg}$ BID performed by M D Anderson Cancer Center (MDACC), Houston, TX $(n=62)$ [13]. For nilotinib, published clinical trials in newly diagnosed CP-CML comprise: (i) ENESTnd (Evaluating nilotinib efficacy and safety in clinical trials - newly diagnosed patients), an international, multicenter, randomized phase 3 trial of nilotinib $300 \mathrm{mg}$ BID vs nilotinib $400 \mathrm{mg}$ BID vs imatinib $400 \mathrm{mg}$ QD ( $\mathrm{n}=846$ ) [14]; (ii) a single-arm phase 2 trial of nilotinib $400 \mathrm{mg}$ BID performed by $\operatorname{MDACC}(\mathrm{n}=61)$ [15]; and (iii) a second single-arm phase 2 trial of nilotinib $400 \mathrm{mg}$ BID performed by the Italian GIMEMA (Gruppo Italiano malattie e matologiche dell'adulto) group $(n=73)$ [4]. No data have been published from an international, multicenter, randomized trial of bosutinib vs imatinib (NCT00574873).

In this review, recent data for first-line treatment with dasatinib or nilotinib will be discussed, with a specific focus on safety and tolerability.

\section{Efficacy of dasatinib and nilotinib compared with imatinib in the first-line setting}

In randomized trials, both dasatinib and nilotinib have shown superior efficacy compared with imatinib as firstline treatment for patients with CP-CML (Tables 1 and 2).

In the DASISION trial, responses were more frequent with dasatinib vs imatinib treatment, including higher

Table 1 Rates of complete cytogenetic response (CCyR) and major molecular response (MMR) to imatinib and dasatinib in the DASISION trial

\begin{tabular}{cll}
\hline & \% of patients & \\
\hline & $\begin{array}{l}\text { Imatinib } \\
\mathbf{4 0 0} \mathbf{~ m g ~ Q D ~}\end{array}$ & $\begin{array}{l}\text { Dasatinib } \\
\mathbf{1 0 0} \mathbf{~ m g} \text { QD }\end{array}$ \\
\hline CCyR & \\
\hline 3 months & 31 & 54 \\
\hline 6 months & 59 & 73 \\
\hline 9 months & 67 & 78 \\
\hline 12 months & 72 & 83 \\
\hline 3 months & & 8 \\
\hline 6 months & 0.4 & 27 \\
\hline 9 months & 8 & 39 \\
\hline 12 months & 18 & 46 \\
\hline Progression to AP/BP & 28 & 1.9 \\
\hline
\end{tabular}

AP: accelerated phase; BP: blast phase; QD: once daily.
Table 2 Rates of complete cytogenetic response (CCyR) and major molecular response (MMR) to imatinib and nilotinib in the ENESTnd trial

\begin{tabular}{clll}
\hline \multicolumn{4}{c}{ \% of patients } \\
\hline & $\begin{array}{l}\text { Imatinib } \\
\mathbf{4 0 0} \mathbf{~ m g ~ Q D ~}\end{array}$ & $\begin{array}{l}\text { Nilotinib } \\
\mathbf{3 0 0} \mathbf{~ m g} \text { BID }\end{array}$ & $\begin{array}{l}\text { Nilotinib } \\
\mathbf{4 0 0} \mathbf{~ m g} \text { BID }\end{array}$ \\
\hline CCyR & & & \\
\hline 6 months & 45 & 67 & 63 \\
\hline 12 months & 65 & 80 & 78 \\
\hline MMR & & & 5 \\
\hline 3 months & 1 & 9 & 30 \\
\hline 6 months & 12 & 33 & 38 \\
\hline 9 months & 18 & 43 & 43 \\
\hline 12 months & 22 & 44 & $<1$ \\
\hline Progression to AP/BP & 4 & $<1$ &
\end{tabular}

AP: accelerated phase; BP: blast phase; QD: once daily.

12-month rates of complete cytogenetic response $(\mathrm{CCyR}$ $83 \%$ vs $72 \%$; $\mathrm{P}=0.001$ ) and major molecular response (MMR; 46\% vs 28\%; P < 0.0001). Dasatinib also showed superiority over imatinib in the primary trial endpoint, the rate of confirmed CCyR (CCyR detected in two consecutive assessments), with 12 -month rates of $77 \%$ vs $66 \%$, respectively $(P=0.007)$. CCyR and MMR both occurred faster with dasatinib compared with imatinib. After a median 14 months of treatment, $1.9 \%$ of patients had progressed to AP/blast phase (BP) with dasatinib compared with $3.5 \%$ with imatinib. No patient in whom a MMR was achieved progressed to AP/BP [12]. In the ENESTnd trial, the primary endpoint was the rate of MMR at 12 months, and both nilotinib arms (300 mg and $400 \mathrm{mg}$ ) had significantly higher rates compared with the imatinib arm $(43-44 \%$ vs $22 \%$; $\mathrm{P}<0.001)$. Rates of CCyR achieved by 12 months were also significantly higher for nilotinib vs imatinib $(78-80 \%$ vs $65 \%$; $\mathrm{P}<$ 0.001 ), and CCyR and MMR occurred faster in the nilotinib arms. After a median 14 months of treatment, fewer nilotinib-treated patients had progressed to AP/BP phase compared with imatinib-treated patients (< $1 \%$ vs $4 \%$; $\mathrm{P} \leq 0.01$ in an analysis of time to progression). Similar to DASISION, no patient who had a MMR had progression to AP/BP [14]. Five-year follow-up is planned in both trials. Because available data suggest that both dasatinib and nilotinib have broadly similar efficacy in terms of their superiority over imatinib, it is likely that safety and tolerability considerations for these agents will become increasingly important when selecting first-line treatment for CML.

\section{The importance of adherence}

Across various chronic diseases requiring long-term treatment, poor adherence is associated with worse outcomes [16]. Similarly, recent studies have shown that 
lack of adherence to imatinib treatment results in significantly lower response rates in patients with CP-CML. In a prospective observational study (Adherence assessment with Glivec: indicators and outcomes; ADAGIO), adherence to imatinib treatment was analyzed in 169 patients with CML during a 90-day period and correlated with overall responses to treatment. Only $14 \%$ of patients were found to be perfectly adherent based on pill counts $(100 \%$ of imatinib taken), with $71 \%$ of patients taking less imatinib than prescribed and 15\% taking more imatinib than prescribed. Importantly, worse adherence was associated with worse treatment responses; patients who had a suboptimal response to imatinib had significant higher mean percentage of imatinib not taken than those with an optimal response (23\% vs $7 \%$; $\mathrm{P}=0.005$ ). Similarly, patients who failed to achieve a CCyR on imatinib had a higher mean percentage of pills not taken than patients who achieved a CCyR (24\% vs 9\%; P = 0.012) [17]. In another prospective observational study performed at a single institution, 87 patients with CP-CML who had achieved a $\mathrm{CCyR}$ on imatinib were monitored for adherence for 90 days using a microelectronic monitoring device. The adherence rate was $\leq 90 \%$ in $26 \%$ and $\leq 80 \%$ in $14 \%$. There was a strong correlation between adherence to imatinib and probabilities of MMR and CMR; patients with $\leq 90 \%$ adherence had a lower 6-year rate of MMR than patients with $>90 \%$ adherence $(14 \%$ vs $94 \%$; $\mathrm{P}=$ 0.002 ), no patient with $\leq 90 \%$ adherence achieved a CMR, and no patient with $\leq 80 \%$ adherence achieved a MMR. Significantly worse adherence rates were found in patients with various adverse events (AEs), including asthenia, nausea, muscle cramps, and bone or joint pains, and also in patients who took imatinib independently of meals. Patients who had their imatinib dose increased had significantly worse adherence than patients who remained on imatinib $400 \mathrm{mg}$ QD (86\% vs $99 \% ; \mathrm{P}=0.021$ ) [18]. In a retrospective analysis of imatinib treatment in clinical practice using US administrative claims data, adherence to imatinib in 267 patients was calculated using the medication possession rate (MPR), ie, the total days supply of imatinib in a 1-year period divided by 365 . Overall, the mean MPR was $78 \%$ and $31 \%$ of patients had a treatment interruption of at least 30 consecutive days. Among the study population, nonadherence was higher in patients with higher numbers of concomitant medications, women, patients with more complex disease, and patients with a higher starting dose of imatinib $(\geq 600 \mathrm{mg} / \mathrm{d})$. Although the reasons for worse adherence in women were not examined, the authors suggested that women may be more concerned than men with AEs characteristic of imatinib treatment, such as rash, edema, and weight gain [19].
The importance of adherence to imatinib in response to treatment is further illustrated by the results of a phase 3 randomized trial of imatinib $400 \mathrm{mg}$ QD vs $800 \mathrm{mg} / \mathrm{d}$ (400 mg BID) in patients with newly diagnosed CP-CML (Tyrosine kinase inhibitor optimization and selectivity [TOPS]). Rates of MMR and CCyR at 12 months were similar between the two arms. However, treatment responses in patients from the $800 \mathrm{mg} / \mathrm{d}$ arm correlated with the dose of imatinib that could be tolerated, with higher MMR rates achieved in patients with an average dose intensity of $600 \mathrm{mg} / \mathrm{d}$ or higher (62-63\%) compared with $400-599 \mathrm{mg} / \mathrm{d}(38 \%)$ or $<400 \mathrm{mg} / \mathrm{d}$ (21\%). In the 400 vs $800 \mathrm{mg}$ arms, $18 \%$ vs $61 \%$ of patients had a dose reduction, $52 \%$ vs $73 \%$ reported at least one day with zero dose, $38 \%$ vs $67 \%$ had dose interruption lasting longer than 5 days, and $16 \%$ vs $20 \%$ discontinued treatment. The main reason for dose reduction in the $800 \mathrm{mg} / \mathrm{d}$ arm, but not the $400 \mathrm{mg} / \mathrm{d}$ arm, was AEs or laboratory abnormalities. These data suggest that the higher number of days off medication (ie, lower adherence) in the high-dose imatinib arm counteracted any positive effect of higher dosing [20].

Nonadherence is a possible cause for reduced response to imatinib and should be considered in patients with suboptimal response to imatinib [17]. The AE profiles and tolerability of newer treatments are therefore important considerations for clinical practice in the first-line setting in terms of both efficacy and safety.

\section{Safety and tolerability of dasatinib and nilotinib compared with imatinib in the first-line setting}

Although dasatinib and nilotinib have been available for use in therapy of CML in the second-line settings for several years, new studies have provided the first direct comparison with imatinib in the first-line setting. In general, imatinib, dasatinib, and nilotinib are associated with broadly similar types of AEs, although the relative occurrence of different AEs varies between agents and some AEs are specific to one drug (Tables 3 and 4). For best management of CML patients receiving TKI therapy, knowledge of potential toxicities, how to avoid them, how to deal with them should they arise, and how they may affect response and outcome, are important factors. In general, BCR-ABL inhibitors are well tolerated and result in a limited number of higher-grade toxicities (grades 3-4). Experience with imatinib in the IRIS trial and with dasatinib and nilotinib in the second-line setting suggest that AEs tend to occur early during the course of treatment and late-onset toxicity is uncommon [21-23]. Longer-term follow-up is needed to confirm that the same is true for dasatinib and nilotinib during first-line treatment. In general, most AEs 
Table 3 Drug-related nonhematologic adverse events, that occurred in $\geq 10 \%$ of patients in any treatment arm, hematologic adverse events, and biochemical abnormalities, during the DASISION trial

\begin{tabular}{|c|c|c|}
\hline \multirow[b]{2}{*}{ Adverse event } & \multicolumn{2}{|c|}{ All grade (grade $3-4$ ), $\%$ of patients } \\
\hline & $\begin{array}{l}\text { Imatinib } \\
400 \mathrm{mg} \text { QD }\end{array}$ & $\begin{array}{l}\text { Dasatinib } \\
100 \mathrm{mg} \text { QD }\end{array}$ \\
\hline \multicolumn{3}{|l|}{ Nonhematologic } \\
\hline Nausea & $20(0)$ & $8(0)$ \\
\hline Diarrhea & $17(1)$ & $17(<1)$ \\
\hline Vomiting & $10(0)$ & $5(0)$ \\
\hline Rash & $17(1)$ & $11(0)$ \\
\hline Headache & $10(0)$ & $12(0)$ \\
\hline Fatigue & $10(0)$ & $8(<1)$ \\
\hline Musculoskeletal pain & $14(<1)$ & $11(0)$ \\
\hline Muscle inflammation & $17(<1)$ & $4(0)$ \\
\hline Fluid retention & $42(1)$ & $19(1)$ \\
\hline Superficial edema & $36(<1)$ & $9(0)$ \\
\hline Pleural effusion & $0(0)$ & $10(0)$ \\
\hline Other & $8(<1)$ & $5(1)$ \\
\hline \multicolumn{3}{|l|}{ Hematologic } \\
\hline Neutropenia & $58(20)$ & $65(21)$ \\
\hline Thrombocytopenia & $62(10)$ & $70(19)$ \\
\hline Anemia & $84(7)$ & $90(10)$ \\
\hline \multicolumn{3}{|l|}{ Biochemical abnormalities } \\
\hline Elevated AST & NL (1) & $\mathrm{NL}(<1)$ \\
\hline Elevated ALT & NL (1) & $\mathrm{NL}(<1)$ \\
\hline Elevated bilirubin & $N L(0)$ & NL (1) \\
\hline Elevated lipase & $\mathrm{NL}(0)$ & NL (0) \\
\hline Hyperglycemia & $\mathrm{NL}(0)$ & $\mathrm{NL}(0)$ \\
\hline Elevated amylase & $\mathrm{NL}(0)$ & $\mathrm{NL}(0)$ \\
\hline Decreased phosphorus & $\mathrm{NL}(21)$ & $\mathrm{NL}(4)$ \\
\hline
\end{tabular}

ALT: alanine aminotransferase; AST: aspartate aminotransferase; NL: not listed; QD: once daily.

occurring during $\mathrm{BCR}-\mathrm{ABL}$ inhibitor therapy can be managed with dose interruption and reduction and/or supportive care.

\section{Cytopenias}

Cytopenias such as neutropenia, thrombocytopenia, and anemia are the most common grade 3-4 AEs observed in patients receiving imatinib, dasatinib, or nilotinib. In the DASISION trial, grade 3-4 cytopenia with dasatinib vs imatinib included similar rates of neutropenia ( $20 \%$ vs $21 \%$ ) and anemia ( $10 \%$ vs $7 \%$ ), whereas thrombocytopenia was more common with dasatinib than with imatinib (19\% vs $10 \%)$ [12]. Few patients discontinued treatment due to cytopenia (1.5\% with dasatinib and $1.2 \%$ with imatinib) [12]. In the MDACC study of dasatinib, grade 3-4 neutropenia,
Table 4 Drug-related nonhematologic adverse events, that occurred in $\geq 10 \%$ of patients in any treatment arm, hematologic adverse events, and biochemical abnormalities, during the ENESTnd trial

\begin{tabular}{|c|c|c|c|}
\hline \multirow{2}{*}{ Adverse event } & \multicolumn{3}{|c|}{ All grade (grade $3-4), \%$ of patients } \\
\hline & $\begin{array}{l}\text { Imatinib } \\
400 \mathrm{mg} \\
\text { QD }\end{array}$ & $\begin{array}{l}\text { Nilotinib } \\
300 \mathrm{mg} \\
\text { BID }\end{array}$ & $\begin{array}{l}\text { Nilotinib } \\
400 \mathrm{mg} \\
\text { BID }\end{array}$ \\
\hline \multicolumn{4}{|l|}{ Nonhematologic } \\
\hline Nausea & $31(0)$ & $11(<1)$ & $19(1)$ \\
\hline Diarrhea & $21(1)$ & $8(1)$ & $6(0)$ \\
\hline Vomiting & $14(0)$ & $5(0)$ & $9(1)$ \\
\hline Rash & $11(1)$ & $31(<1)$ & $36(3)$ \\
\hline Pruritus & $5(0)$ & $15(<1)$ & $13(<1)$ \\
\hline Alopecia & $4(0)$ & $8(0)$ & $13(0)$ \\
\hline Headache & $8(0)$ & $14(1)$ & $21(1)$ \\
\hline Fatigue & $8(<1)$ & $11(0)$ & $9(1)$ \\
\hline Muscle spasm & $24(1)$ & $7(0)$ & $6(1)$ \\
\hline Myalgia & $10(0)$ & $10(<1)$ & $10(0)$ \\
\hline Peripheral edema & $14(0)$ & $5(0)$ & $5(0)$ \\
\hline Eyelid edema & $13(<1)$ & $1(0)$ & $2(<1)$ \\
\hline Periorbital edema & $12(0)$ & $<1(0)$ & $1(0)$ \\
\hline \multicolumn{4}{|l|}{ Hematologic } \\
\hline Neutropenia & $68(20)$ & $43(12)$ & $38(10)$ \\
\hline Thrombocytopenia & $56(9)$ & $48(10)$ & $49(12)$ \\
\hline Anemia & $47(5)$ & $38(3)$ & $38(3)$ \\
\hline \multicolumn{4}{|l|}{ Biochemical abnormalities } \\
\hline Elevated AST & $23(1)$ & $40(1)$ & $48(3)$ \\
\hline Elevated ALT & $20(2)$ & $66(4)$ & $73(9)$ \\
\hline Elevated bilirubin & $10(<1)$ & $53(4)$ & $62(8)$ \\
\hline Elevated lipase & $11(3)$ & $24(6)$ & $29(6)$ \\
\hline Hyperglycemia & $20(0)$ & $36(6)$ & $41(4)$ \\
\hline Elevated creatinine & $13(<1)$ & $5(0)$ & $5(0)$ \\
\hline Elevated amylase & $12(1)$ & $15(<1)$ & $18(1)$ \\
\hline $\begin{array}{l}\text { Elevated alkaline } \\
\text { phosphatase }\end{array}$ & $33(<1)$ & $21(0)$ & $27(0)$ \\
\hline Decreased phosphorus & $45(8)$ & $32(5)$ & $34(5)$ \\
\hline
\end{tabular}

ALT: alanine aminotransferase; AST: aspartate aminotransferase; BID: twice daily; QD: once daily.

thrombocytopenia, and anemia occurred in $21 \%, 10 \%$, and $6 \%$ of patients, respectively [13]. In the ENESTnd trial, grade 3-4 neutropenia was less common in the nilotinib 300 or $400 \mathrm{mg}$ BID arms (12\% and $10 \%$, respectively) compared with the imatinib arm (20\%), whereas grade $3-4$ thrombocytopenia ( $10 \%$ vs $12 \%$ vs $9 \%$ ) and anemia ( $3 \%$ vs $3 \%$ vs $5 \%$ ) were similar between treatment arms [14]. In the MDACC study of nilotinib, grade 3-4 neutropenia, thrombocytopenia, and anemia occurred in $12 \%, 11 \%$, and $5 \%$ of patients, respectively [15], whereas low rates $(4 \%, 2 \%$, and $0 \%)$ were reported in the GIMEMA study [4]. 


\section{Dermatologic toxicity}

Rash was one of the most common nonhematologic AEs $[24,25]$. In the IRIS study, rash occurred in $34 \%$, although grade 3-4 rash was infrequent (2\%). Pruritus (7\%) and alopecia (4\%) were also noted in smaller numbers of patients [25]. In the DASISION trial, first-line dasatinib treatment resulted in fewer cases of rash compared with imatinib treatment ( $11 \%$ vs $17 \%)$, with grade $3-4$ rash occurring in $0 \%$ vs $1 \%$, respectively. No rates were provided for pruritis or alopecia, suggesting that the frequencies were $<10 \%$ in both arms [12]. In the MDACC study, $58 \%$ of patients experienced "skin toxicity" (grouped term) with dasatinib, which was grade $3-4$ in $2 \%$. In addition, $8 \%$ experienced pruritus of which $2 \%$ was grade $3-4$ [13]. Dermatologic toxicity seems to be more common with nilotinib than imatinib. In the ENESTnd trial, rash occurred in 31\% taking nilotinib $300 \mathrm{mg}$ BID, 36\% taking nilotinib $400 \mathrm{mg} \mathrm{BID}$, and 11\% taking imatinib (grade 3-4 in $<1 \%$ vs $3 \%$ vs $1 \%$, respectively). Pruritus was also more common in both nilotinib arms (15\% with $300 \mathrm{mg}$ BID and 13\% with $400 \mathrm{mg}$ BID) compared with imatinib (5\%), as was alopecia ( $8 \%$ with nilotinib $300 \mathrm{mg}$ BID, 13\% with nilotinib $400 \mathrm{mg}$ BID, and $4 \%$ with imatinib) [14]. In single-arm trials of first-line nilotinib $400 \mathrm{mg}$ BID, rash occurred in $49 \%$ (2\% grade $3-4$ ) of patients in the MDACC trial [15] and in $42 \%$ (5\% grade 3 ) in the GIMEMA trial [4]. Pruritus also occurred in $21 \%$ of patients in the GIMEMA trial ( $4 \%$ grade 3 ).

\section{Gastrointestinal symptoms}

Nausea, diarrhea, and vomiting are common in patients receiving $\mathrm{BCR}-\mathrm{ABL}$ inhibitor therapy, although recent data indicate that gastrointestinal (GI) disturbances occur less often in patients receiving dasatinib or nilotinib compared with those receiving imatinib. In the DASISION trial, nausea ( $8 \%$ v $20 \%)$ and vomiting (5\% vs $10 \%$ ) both occurred less frequently with dasatinib compared with imatinib, whereas rates of diarrhea were similar (17\% in both arms). Grade 3-4 diarrhea was reported in $<1-1 \%$, and no patients in either arm experienced grade 3-4 nausea or vomiting [12]. In the MDACC trial of dasatinib, higher rates of GI AEs were reported, including diarrhea in 53\% (2\% grade 3-4), nausea in $45 \%$ ( $0 \%$ grade $3-4)$, and vomiting in $21 \%(0 \%$ grade 3-4) [13]. In the ENESTnd trial, rates of GI AEs were lower with nilotinib $300 \mathrm{mg}$ and $400 \mathrm{mg}$ vs imatinib, including nausea ( $11 \%$ vs $19 \%$ vs $31 \%)$, diarrhea ( $8 \%$ vs $6 \%$ vs $21 \%$ ), and vomiting ( $5 \%$ vs $9 \%$ vs $14 \%$ ), of which $0-1 \%$ were grade $3-4$ cases in all arms [14]. In the MDACC study of first-line nilotinib, nausea and diarrhea were reported in $38 \%$ and $21 \%$ of patients, respectively, (no grade $3-4)$, and diarrhea occurred in $7 \%$ (2\% grade $3-4$ ) [15]. In the GIMEMA study, $11 \%$ of patients experienced nausea/vomiting (1\% grade $3-4)$ and $7 \%$ had diarrhea ( $2 \%$ grade 3$)$ [4].

\section{Edema}

Fluid retention is common with imatinib, as shown by $56 \%$ of patients receiving imatinib in the IRIS trial experiencing superficial edema and 13\% having weight gain [25]. First-line dasatinib and nilotinib treatment are associated with lower rates of edema. In the DASISION, superficial edema (grouped term) was much less frequent with dasatinib (9\%) compared with imatinib (36\%), and rates of grade 3-4 superficial edema were low ( $0 \%$ vs $<1 \%$, respectively) [12]. In the MDACC study of dasatinib, edema was reported in $32 \%$ of patients (no grade 3-4) [13]. In the ENESTnd trial, different types of edema were reported separately. In the nilotinib $300 \mathrm{mg}$ BID, nilotinib $400 \mathrm{mg}$ BID, and imatinib arms, peripheral edema occurred in $5 \%$ vs $5 \%$ vs $14 \%$, eyelid edema occurred in $1 \%$ vs $2 \%$ vs $13 \%$, and periorbital edema occurred in $<1 \%$ vs $1 \%$ vs $12 \%$ [14]. In the GIMEMA trial, peripheral edema was reported in $4 \%$ of patients receiving nilotinib and all cases were grade 1-2 [4]. Data for edema were not reported in the MDACC study of nilotinib [15].

\section{Pleural effusion}

Pleural effusion is rare with nilotinib and imatinib but is a more prominent side effect of dasatinib treatment $[26,27]$. In the DASISION trial, $10 \%$ of patients in the dasatinib arm had a pleural effusion whereas no patient receiving imatinib reported this $\mathrm{AE}$. Dasatinib-associated pleural effusion was grade 1 in $2 \%$ and grade 2 in $8 \%$ of patients, with no pleural effusion grade 3 or above. The occurrence of pleural effusion did not affect the efficacy of dasatinib, as shown by CCyR being achieved in 24/26 patients (92\%) who had a pleural effusion. In the DASISION trial, pleural effusion was managed using dose adjustments and/or medical intervention, including dose interruption in 19 patients, diuretics in 12 patients, dose reduction in eight patients, corticosteroids in seven patients, and therapeutic thoracentesis in one patient. Discontinuation due to pleural effusion occurred in three patients ( $1 \%$ of the dasatinib arm) [12]. In the MDACC study of first-line dasatinib, the rate of pleural effusion $(13 \%)$ was similar to DASISION, and one case of grade 3/4 pleural effusion was reported. Pleural effusion occurred less frequently in patients who received dasatinib $100 \mathrm{mg}$ QD (6\%) compared with $50 \mathrm{mg}$ BID (19\%), and two patients (3\%) discontinued treatment due to pleural effusion [13]. In the ENESTnd study, pleural effusion occurred in a small number $(<1 \%)$ of nilotinib-treated patients [28] and was not reported in the single-arm studies of nilotinib. 


\section{Cardiac toxicity}

In 2006, a report was published describing ten individuals who developed severe congestive heart failure (CHF) on imatinib treatment. Based on laboratory studies, the authors suggested that this effect could occur as a result of inhibition of physiologic ABL activity in cardiac tissue [29]. Subsequent retrospective analyses estimated that the frequency of CHF or left ventricular dysfunction during imatinib therapy for CML was $0.5-1.1 \%$ [30-32].

In TKI studies, instances of QT prolongation were reported [33-37]. In particular, in studies of nilotinib in patients with imatinib resistance or intolerance, sudden death was reported in $0.6 \%$ of patients, with a similar rate of occurrence in an expanded-access program. The timing of sudden death relative to initiation of nilotinib suggested that ventricular repolarization abnormalities may have contributed to their occurrence [34]. In recent TKI trials, patients with significant cardiac disease were excluded from participating.

In randomized trials of nilotinib or dasatinib vs imatinib, close monitoring for QT prolongation and changes in left ventricular ejection fraction was performed. During nilotinib or imatinib treatment in the ENESTnd study, no patient had a QTc interval of $>500 \mathrm{msec}$ and no decrease from the baseline in the mean left ventricular ejection fraction was observed at any time. Eleven patients across all three study arms had an ischemic heart disease event, although no further details were provided regarding relative frequency between arms [14]. In the MDACC study of front-line nilotinib, there were two instances of hypertension and one instance of QTc prolongation (all classed as grade 1-2) [15]. In the GIMEMA study of nilotinib, 584 electrocardiograms from 73 patients were reviewed. In addition to transient/irreverent abnormalities noted in $22 \%$ of patients, QTc interval prolongation to $>450 \mathrm{msec}$ was noted in 2 cases [4]. In the DASISON trial, $2 \%$ vs $4 \%$ of dasatinib and imatinib arms had QTc intervals between 450-500 msec, and one patient $(0.4 \%)$ in each group had a QTc interval of $>500$ msec. Median changes in QTc interval from baseline were $3 \mathrm{msec}$ in the dasatinib group and 8 msec in the imatinib group [12].

\section{Bleeding}

Bleeding was noted in studies of dasatinib in the second-line setting, mostly in patients with severe thrombocytopenia and more commonly in patients with advanced disease [38]. In vitro data suggest that dasatinib reversibly inhibits platelet activation [39]. In the DASISION trial, GI bleeding or other bleeding events occurred at a similar frequency in both treatment arms (5\%). One patient in the dasatinib group and two patients in the imatinib group reported a grade 3-4 bleeding event [12].

\section{Other nonhematologic AEs}

Mild to moderate nonhematologic AEs such as headache, fatigue, muscle pains/cramps, and joint pain are commonly seen with BCR-ABL inhibitor treatment. These effects are usually easily managed without dose reduction and rarely cause dose interruptions. Recent data suggest that some of these AEs occur at different rates with dasatinib or nilotinib compared with imatinib. In the DASISION study, musculoskeletal AEs were less common with dasatinib compared with the imatinib arm, including myalgia ( $6 \%$ vs $12 \%$ ), muscle inflammation ( $4 \%$ vs $17 \%)$, and musculoskeletal pain ( $11 \%$ v $14 \%)$. Rates of fatigue ( $8 \% \mathrm{v} 10 \%)$ and headache $(12 \%$ vs $10 \%)$ were similar in both arms. With each of these AEs, $\leq 1 \%$ of patients had a grade 3-4 event [12]. In the MDACC study of dasatinib, pain in joint/muscle (combined grouping; $74 \%)$, fatigue (73\%), and headache $(56 \%)$ were reported at high rates (grade $3-4$ in $6 \%, 6 \%$, and $2 \%$, respectively) [13]. In the ENESTnd trial, muscle spasm occurred at a lower frequency in the nilotinib arms (6-7\%) compared with the imatinib arm (24\%). Myalgia occurred at a similar rate across all three arms $(10 \%)$, as did fatigue $(8-11 \%)$. However, headache occurred at a higher frequency in the nilotinib $300 \mathrm{mg}$ BID (14\%) and $400 \mathrm{mg}$ BID (21\%) treatment groups than in the imatinib treatment group (8\%). Rates of grade 3-4 events with these AEs were $\leq 1 \%$ [14]. Similar to the MDACC study of dasatinib, the study of nilotinib at the same institution reported substantially higher rates of fatigue (67\%; grade $3-4$ in $3 \%$ ) and headache (39\%; no grade 3-4) than in the randomized study. Musculoskeletal AEs were reported as separate categories; $10 \%$ of patients experienced muscle cramp ( $0 \%$ grade $3-$ 4) and $10 \%$ experienced joint pain (3\% grade 3-4) [15]. In the GIMEMA study, $41 \%$ of patients taking nilotinib experienced bone/muscle/joint pain (combined grouping), of which $4 \%$ were grade 3 . In addition, $30 \%$ experienced headache and $22 \%$ experienced fatigue (no grade 3-4 in each case) [4].

\section{Biochemical abnormalities}

Rates of biochemical abnormalities vary in patients receiving different $\mathrm{BCR}-\mathrm{ABL}$ inhibitors and seem to be most common during nilotinib treatment. In the DASISION trial, grade 3-4 hypophosphatemia occurred in $4 \%$ of patients treated with dasatinib compared with $21 \%$ of the patients treated with imatinib. Rates of other grade 3-4 biochemical abnormalities were low in both treatment arms, including markers of hepatic toxicity (elevated alanine aminotransferase $[\mathrm{ALT}]$ or aspartate 
aminotransferase [AST] each $<1 \%$ vs $1 \%$, elevated total bilirubin $1 \%$ vs $0 \%$ ) and pancreatic toxicity (no grade $3 / 4$ elevations in lipase or amylase, or cases of hyperglycemia were recorded). Rates of all-grade biochemical abnormalities were not reported [40]. Four imatinibtreated patients but no dasatinib-treated patients discontinued therapy because of biochemical abnormalities [12]. In the MDACC study of dasatinib, hypophosphatemia occurred in $6 \%$ (2\% grade $3-4)$ of patients, hyperglycemia occurred in $24 \%$ (2\% grade $3-4$ ), and elevated ALT or AST occurred in $16 \%$ and $15 \%$, respectively (no grade 3-4 cases) [13].

In the ENESTnd trial, more nilotinib-treated patients than imatinib-treated patients had biochemical abnormalities associated with liver and pancreatic toxicity. With nilotinib $300 \mathrm{mg}$ BID or $400 \mathrm{mg}$ BID or imatinib, ALT was elevated in $66 \%$ vs $73 \%$ vs $20 \%$ of patients, respectively (grade $3-4$ in $4 \%$ vs $9 \%$ vs $2 \%$ ), AST was elevated in $40 \%$ vs $48 \%$ vs $23 \%$ (grade $3-4$ in $1 \%$ vs $3 \%$ vs $1 \%$ ), and bilirubin was elevated in $53 \%$ vs $62 \%$ vs $10 \%$, (grade $3-4$ in $4 \%$ vs $8 \%$ vs $<1 \%)$. Elevated lipase was observed in $24-29 \%$ of patients receiving nilotinib (6\% grade $3-4$ ) compared with $11 \%$ of patients receiving imatinib $(3 \%$ grade $3-4)$. Respective rates of hyperglycemia were $36-41 \%$ (4-6\% grade $3-4$ ) vs $20 \%$ (no grade $3-4$ ) and elevated amylase occurred in $15-18 \%$ vs $12 \%$ (grade $3-4$ in $<1-1 \%)$ of patients. Hypophosphatemia occurred in $32-34 \%$ of nilotinib arms (5\% grade $3-4$ ) and $45 \%$ of the imatinib arm (8\% grade $3-4)$. All newly occurring grade 3-4 biochemical abnormalities occurred within the first 2 months of therapy. Discontinuations due to biochemical abnormalities occurred in $2 \%$ of both nilotinib arms and $1 \%$ of the imatinib arm [14]. In other studies of nilotinib as front-line therapy, ALT elevation occurred in $42-48 \%$ (0-8\% grade 3$)$ of patients, AST elevation occurred in $29-46 \%$ (0-3\% grade 3$)$, and bilirubin elevation occurred in $39-53 \%$ (grade $3-4$ in $7-16 \%$ ) $[4,15]$. Elevated markers of pancreatic toxicity were reported in both studies. However, hyperglycemia was more common in the MDACC study (44\%, grade $3-4$ in $5 \%$ ) than elevated lipase $(10 \%$, grade $3 / 4$ in $5 \%)$ or amylase $(3 \%$, grade $3 / 4$ in $2 \%$ ), whereas hyperglycemia ( $12 \%$, grade 3 in $3 \%$ ) was less common in the GIMEMA study than elevated lipase $(29 \%$, grade $3-4$ in $8 \%$ ) or amylase $(18 \%$, grade 3 in 4\%) [4,15]. One patient in the GIMEMA study discontinued treatment following lipase elevation.

Bilirubin elevation on nilotinib may be due in part to nilotinib inhibition of UGT1A1 activity. UGT1A1 catalyzes the conjugation of hepatic bilirubin and polymorphisms in the promoter region of UGT1A1 are associated with Gilbert's Syndrome (inherited mild, chronic, unconjugated hyperbilirubinemia in the absence of liver disease or overt hemolysis). Reduced UGT1A1 expression due to polymorphisms is associated with elevation of bilirubin in plasma [41,42]. UGT1A1 promoter polymorphism has been found to increase the risk of nilotinib-induced bilirubin elevation [43].

\section{Dose adjustments and discontinuations due to toxicity}

The rate of discontinuations because of drug toxicity provides a measure of the frequency of the most problematic AEs. In the DASISION trial, discontinuations following study drug toxicity occurred in $5.0 \%$ of the dasatinib arm and $4.3 \%$ of the imatinib arm. Of these, hematologic toxicity led to discontinuation in $1.6 \%$ vs $1.2 \%$, and nonhematologic toxicity led to discontinuation in $3.5 \%$ vs $3.1 \%$, respectively. Median doses of drug delivered were $99 \mathrm{mg} / \mathrm{d}$ in the dasatinib $100 \mathrm{mg}$ QD arm vs $400 \mathrm{mg} / \mathrm{d}$ in the imatinib $400 \mathrm{mg}$ QD arm. Data for dose interruptions and reductions have not been reported [12]. In the ENESTnd trial, discontinuations due to AEs occurred in 5\% with nilotinib $300 \mathrm{mg}$ BID, 9\% with nilotinib $400 \mathrm{mg}$ BID, and $7 \%$ with imatinib. Median doses of drug delivered were $592 \mathrm{mg} / \mathrm{d}$ in the nilotinib $300 \mathrm{mg}$ BID arm, $779 \mathrm{mg} / \mathrm{d}$ in the nilotinib $400 \mathrm{mg}$ BID arm, and $400 \mathrm{mg}$ in the imatinib $400 \mathrm{mg}$ QD arm. Respective rates of dose reduction/interruption were $59 \%, 66 \%$, and $52 \%$. Median cumulative durations of interruptions due to AEs or biochemical abnormalities were 19 days, 22 days, and 15 days, respectively [14].

\section{Future directions with BCR-ABL inhibitors Bosutinib}

Data are awaited from the randomized phase 3 trial of bosutinib vs imatinib for first-line treatment for newly diagnosed CML [37]. However, data have been reported for the efficacy and safety of bosutinib in patients with CP-CML who had prior imatinib treatment. Response rates with bosutinib were comparable to those seen in trials of dasatinib and nilotinib in the second-line setting, including CCyR in 50\% and MMR in 52\% of evaluated patients, of which $32 \%$ were complete. At 24 months, rates of progression-free and overall survival were $80 \%$ and 95\%, respectively. Responses were similar in patients with or without BCR-ABL mutations. Safety data indicate that bosutinib has a distinct safety profile compared with currently approved BCR-ABL inhibitors. AE rates should be interpreted with caution based on previous observations with dasatinib and nilotinib that AEs generally occur more frequently with second-line (post-imatinib) treatment compared with first-line treatment. Grade 3-4 thrombocytopenia, neutropenia, and anemia occurred in $24 \%, 16 \%$, and $12 \%$, respectively of patients receiving bosutinib. GI AEs were common with bosutinib treatment, including diarrhea in $84 \%$ of patients ( $9 \%$ grade $3-4)$, nausea in $44 \%$ ( $2 \%$ grade $3-4$ ), and vomiting in $36 \%$ (3\% grade $3-4)$. In addition, $34 \%$ of patients suffered from 
rash (9\% grade $3-4), 21 \%$ had abdominal pain (1\% grade $3-4), 21 \%$ had fatigue (1\% grade $3-4), 14 \%$ had headache (no grade $3-4$ ), and $13 \%$ had joint pain (< 1\% grade $3-4$ ). Rates of fluid retention AEs were not reported, indicating a frequency of $<10 \%$. Of grade 3-4 biochemical abnormalities, elevated ALT occurred in $10 \%$ of patients, elevated AST in 5\%, elevated lipase in $7 \%$, elevated glucose in $3 \%$, decreased phosphate in $8 \%$, and hypermagnesemia in $12 \%$. In addition, $19 \%$ of patients receiving bosutinib in this study discontinued treatment due to AEs and $45 \%$ had a dose reduction due to AEs. The median dose of bosutinib was $454 \mathrm{mg} / \mathrm{d}$ (starting dose was $500 \mathrm{mg} / \mathrm{d}$ ) [44]. Overall, preliminary data from this phase $1 / 2$ trial indicate that bosutinib is an active agent for patients with CP-CML who have failed on prior imatinib treatment, with activity against a range of BCR-ABL mutations, and an acceptable toxicity profile.

\section{Inhibitors for T315I mutant}

Resistance to imatinib or relapse in patients with CML arises most frequently because of point mutations within the BCR-ABL coding sequence [45-48]. In vitro data has shown that dasatinib, nilotinib, and bosutinib effectively inhibit the majority of mutated forms of BCR-ABL that have been associated with imatinib resistance in the clinic $[6,9,49]$. However, the T315I point mutation confers resistance to imatinib, dasatinib, nilotinib, and bosutinib [50,51]. Although data are not yet available to indicate how frequently T315I will cause resistance to the newer agents, this mutation represents an "Achilles' heel" for CML therapy.

Several TKIs that are active against the T315I-mutated form of BCR-ABL are being developed. MK-0457, a potent inhibitor of BCR-ABL and aurora kinases, was the first agent to show clinical activity against the T315I mutation; however, development of this drug was halted due to cardiac toxicity [52]. Other BCR-ABL/aurora kinases inhibitors with activity against T315I are in clinical development, including XL228, PHA-739358 (danusertib), and AT9283 [53-57]. Ponatinib (AP24534) is a multitargeted $\mathrm{BCR}-\mathrm{ABL} / \mathrm{SRC}$ kinase inhibitor with potent in vitro activity against all tested mutants of BCR-ABL including T315I, and clinical activity has been reported in patients with a T315I mutation [58-60]. Further clinical studies of ponatinib are ongoing, most notably a single-arm phase 2 study in patients with CML or $\mathrm{Ph}+$ acute lymphoblastic leukemia (ALL) who either are resistant or intolerant to either dasatinib or nilotinib, or who harbor the T315I mutation (Ponatinib Ph+ ALL and CML evaluation [PACE]; NCT01207440). Switch pocket kinase inhibitors, such as DCC-2036 and DCC-2157, target the sites involved in controlling the conformation of BCR-ABL, which ultimately controls the activity state of the kinase. These agents are active against cells expressing a variety of
BCR-ABL mutations, including T135I. A phase 1 study of DCC-2036 in patients with T315I or failure on two different TKIs is underway (NCT00827138) [61,62]. Omacetaxine (previously homoharringtonine) is a naturally occurring alkaloid derived from evergreen trees that induces apoptosis in leukemic cells, including those harbouring the T315I mutation [63-65]. In a phase $2 / 3$ trial in patients with CML and a T315I mutation, omacetaxine treatment in the subset of patients with CP-CML resulted in a CCyR in 10\% and a MMR in 15\% [66]. The underlying mechanism for omacetaxine inhibitory effects on leukemic cells is still unknown. Studies of omacetaxine in patients with CML, either alone or in combination with other treatments, are ongoing.

\section{Acknowledgements \\ This study was partly supported by the Research Fund for the Doctoral Program of Higher Education of China (GW, No.J20070747) and by New York Medical College Blood Diseases Fund (DL). The authors take full responsibility for the content of this article. StemScientific, funded by Bristol- Myers Squibb, were involved partially in professional writing and editing support. The authors did not receive financial compensation for authoring or publishing the article.}

\section{Author details}

${ }^{1}$ Bone Marrow Transplantation Center, the First Affiliated Hospital, Zhejiang University School of Medicine, Hangzhou 310003, PR China. ${ }^{2}$ Division of Hematology and Oncology, New York Medical College and Westchester Medical Center, Valhalla, NY 10595, USA.

\section{Authors' contributions}

GW, SR and DL involved in concept design, coordination, drafting and critically revising the manuscript.

Received: 19 November 2010 Accepted: 26 November 2010 Published: 26 November 2010

\section{References}

1. Deininger M, O'Brien SG, Guilhot F, Goldman JM, Hochhaus A, Hughes TP, Radich JP, Hatfield AK, Mone M, Filian J, Reynolds J, Gathmann I, Larson RA, Druker BJ: International randomized study of interferon vs STI571 (IRIS) 8-year follow up: sustained survival and low risk for progression or events in patients with newly diagnosed chronic myeloid leukemia in chronic phase treated with imatinib. Blood 2009, 114(Suppl):462, (abstract 1126).

2. Agrawal M, Garg RJ, Cortes J, Quintas-Cardama A: Tyrosine kinase inhibitors: the first decade. Curr Hematol Malig Rep 2010, 5:70-80.

3. le Coutre P, Schwarz M, Kim TD: New developments in tyrosine kinase inhibitor therapy for newly diagnosed chronic myeloid leukemia. Clin Cancer Res 2010, 16:1771-1780.

4. Rosti G, Palandri F, Castagnetti F, Breccia M, Levato L, Gugliotta G, Capucci A, Cedrone M, Fava C, Intermesoli T, Cambrin GR, Stagno F, Tiribelli M, Amabile M, Luatti S, Poerio A, Soverini S, Testoni N, Martinelli G, Alimena G, Pane F, Saglio G, Baccarani M: Nilotinib for the frontline treatment of $\mathrm{Ph}(+)$ chronic myeloid leukemia. Blood 2009, 114:4933-4938.

5. Saglio G, Baccarani M: First-line therapy for chronic myeloid leukemia: new horizons and an update. Clin Lymphoma Myeloma Leuk 2010, 10:169-176.

6. O'Hare T, Walters DK, Stoffregen EP, Jia T, Manley PW, Mestan J, CowanJacob SW, Lee FY, Heinrich MC, Deininger MW, Druker BJ: In vitro activity of Bcr-Abl inhibitors AMN107 and BMS-354825 against clinically relevant imatinib-resistant Abl kinase domain mutants. Cancer Res 2005, 65:4500-4505.

7. Weisberg E, Manley PW, Breitenstein W, Bruggen J, Cowan-Jacob SW, Ray A, Huntly B, Fabbro D, Fendrich G, Hall-Meyers E, Kung AL, Mestan J, 
Daley GQ, Callahan L, Catley L, Cavazza C, Azam M, Neuberg D, Wright RD Gilliland DG, Griffin JD: Characterization of AMN107, a selective inhibitor of native and mutant Bcr-Abl. Cancer Cell 2005, 7:129-141.

8. Puttini M, Coluccia AM, Boschelli F, Cleris L, Marchesi E, Donella-Deana A, Ahmed S, Redaelli S, Piazza R, Magistroni V, Andreoni F, Scapozza L, Formelli F, Gambacorti-Passerini C: In vitro and in vivo activity of SKI-606, a novel Src-Abl inhibitor, against imatinib-resistant Bcr-Abl+ neoplastic cells. Cancer Res 2006, 66:11314-11322.

9. Redaelli S, Piazza R, Rostagno R, Magistroni V, Perini P, Marega M, Gambacorti-Passerini C, Boschelli F: Activity of bosutinib, dasatinib, and nilotinib against 18 imatinib-resistant BCR/ABL mutants. J Clin Oncol 2009, 27:469-471.

10. Tokarski JS, Newitt JA, Chang CY, Cheng JD, Wittekind M, Kiefer SE, Kish K, Lee FY, Borzillerri R, Lombardo LJ, Xie D, Zhang Y, Klei HE: The structure of dasatinib (BMS-354825) bound to activated ABL kinase domain elucidates its inhibitory activity against imatinib-resistant $A B L$ mutants. Cancer Res 2006, 66:5790-5797.

11. Vajpai N, Strauss A, Fendrich G, Cowan-Jacob SW, Manley PW, Grzesiek S, Jahnke W: Solution conformations and dynamics of ABL kinase-inhibitor complexes determined by NMR substantiate the different binding modes of imatinib/nilotinib and dasatinib. J Biol Chem 2008, 283:18292-18302.

12. Kantarjian H, Shah NP, Hochhaus A, Cortes J, Shah S, Ayala M, Moiraghi B, Shen Z, Mayer J, Pasquini R, Nakamae H, Huguet F, Boque C, Chuah C, Bleickardt E, Bradley-Garelik MB, Zhu C, Szatrowski T, Shapiro D, Baccarani M: Dasatinib versus imatinib in newly diagnosed chronic-phase chronic myeloid leukemia. N Engl J Med 2010, 362:2260-2270.

13. Cortes JE, Jones D, O'Brien S, Jabbour E, Ravandi F, Koller C, Borthakur G, Walker B, Zhao W, Shan J, Kantarjian H: Results of dasatinib therapy in patients with early chronic-phase chronic myeloid leukemia. J Clin Oncol 2010, 28:398-404.

14. Saglio G, Kim DW, Issaragrisil S, le CP, Etienne G, Lobo C, Pasquini R, Clark RE, Hochhaus A, Hughes TP, Gallagher N, Hoenekopp A, Dong M, Haque A, Larson RA, Kantarjian HM: Nilotinib versus imatinib for newly diagnosed chronic myeloid leukemia. N Engl J Med 2010, 362:2251-2259.

15. Cortes JE, Jones D, O'Brien S, Jabbour E, Konopleva M, Ferrajoli A, Kadia T, Borthakur G, Stigliano D, Shan J, Kantarjian H: Nilotinib as front-line treatment for patients with chronic myeloid leukemia in early chronic phase. J Clin Oncol 2010, 28:392-397.

16. Osterberg L, Blaschke T: Adherence to medication. N Engl J Med 2005 , 353:487-497.

17. Noens $L$, van Lierde MA, De Bock $R$, Verhoef $G$, Zachee $P$, Berneman Z, Martiat P, Mineur P, Van Eygen K, MacDonald K, De Geest S, Albrecht T, Abraham I: Prevalence, determinants, and outcomes of nonadherence to imatinib therapy in patients with chronic myeloid leukemia: the ADAGIO study. Blood 2009, 113:5401-5411.

18. Marin D, Bazeos A, Mahon FX, Eliasson L, Milojkovic D, Bua M, Apperley JF, Szydlo R, Desai R, Kozlowski K, Paliompeis C, Latham V, Foroni L, Molimard M, Reid A, Rezvani K, de Lavallde H, Guallar C, Goldman J, Khorashad JS: Adherence is the critical factor for achieving molecular responses in patients with chronic myeloid leukemia who achieve complete cytogenetic responses on imatinib. J Clin Oncol 2010, 28:2381-2388.

19. Darkow T, Henk HJ, Thomas SK, Feng W, Baladi JF, Goldberg GA, Hatfield A Cortes J: Treatment interruptions and non-adherence with imatinib and associated healthcare costs: a retrospective analysis among managed care patients with chronic myelogenous leukaemia. Pharmacoeconomics 2007, 25:481-496.

20. Cortes JE, Baccarani M, Guilhot F, Druker BJ, Branford S, Kim DW, Pane F, Pasquini R, Goldberg SL, Kalaycio M, Moiraghi B, Rowe JM, Tothova E, De SC, rudoltz m, Yu R, Krahnke T, Kantarjian HM, Radich JP, Hughes TP: Phase III, randomized, open-label study of daily imatinib mesylate 400 $\mathrm{mg}$ versus $800 \mathrm{mg}$ in patients with newly diagnosed, previously untreated chronic myeloid leukemia in chronic phase using molecular end points: tyrosine kinase inhibitor optimization and selectivity study. $J$ Clin Oncol 2010, 28:424-430.

21. Kantarjian HM, Larson RA, Guilhot F, O'Brien SG, Druker BJ, on Behalf of IRIS Study Group: Declining rates of adverse events (AEs), rare occurrence of serious AEs, and no unexpected long-term side effects at 5 years in patients with newly diagnosed chronic myeloid leukemia in chronic phase initially treated with imatinib in the international randomized study of interferon vs STI571 (IRIS). Blood 2006, 108(Suppl), abstract 2136.

22. Kantarjian HM, Giles FJ, Bhalla KN, Pinilla-lbarz J, Larson RA, Gattermann N, Ottmann OG, Hochhaus A, Radich JP, Saglio G, Hughes TP, Martinelli G, Kim DW, Shou Y, Gallagher NJ, Wang J, Cortes-Franco J, Baccarani M, Coutre PD: Update on imatinib-resistant chronic myeloid leukemia patients in chronic phase on nilotinib therapy at 24 months: clinical response, safety, and long-term outcomes. Blood 2009, 114(Suppl), abstract 1129.

23. Shah NP, Cortes JE, Schiffer CA, le Coutre P, Bahceci E, Lambert A, Saglio G: Four-year follow-up of patients with chronic-phase chronic myeloid leukemia receiving $100 \mathrm{mg}$ of dasatinib once daily. J Clin Oncol 2010, 28(Suppl), abstract 6512.

24. Huang X, Patel S, Ahmed N, Seiter K, Liu D: Severe toxicity of skin rash, fever, and diarrhea associated with imatinib:case report and review of skin toxicities associated with tyrosine kinase inhibitors. Drug Design, Development and Therapy 2008, 2:215-219.

25. O'Brien SG, Guilhot F, Larson RA, Gathmann I, Baccarani M, Cervantes F, Cornelissen JJ, Fischer T, Hochhaus A, Hughes T, Lechner K, Nielsen JL, Rousselot P, Reiffers J, Saglio G, Shepherd J, Simonsson B, Gratwohl A, Goldman JM, Kantarjian H, Taylor K, Verhoef G, Bolton AE, Capdeville R, Druker BJ: Imatinib compared with interferon and low-dose cytarabine for newly diagnosed chronic-phase chronic myeloid leukemia. $N$ Engl J Med 2003, 348:994-1004.

26. Masiello D, Gorospe G, Yang AS: The occurrence and management of fluid retention associated with TKI therapy in CML, with a focus on dasatinib. J Hematol Oncol 2009, 2:46.

27. Wong SF: New dosing schedules of dasatinib for CML and adverse event management. J Hematol Oncol 2009, 2:10.

28. Larson RA, Le Coutre PD, Reiffers J, Hughes TP, Saglio G, Edrich P, Hoenekopp A, Gallagher NJ, Kantarijan H, Hochhaus A: Comparison of nilotinib and imatinib in patients (pts) with newly diagnosed chronic myeloid leukemia in chronic phase (CML-CP): ENESTnd beyond one year. J Clin Oncol 2010, 28(Suppl), abstract 6501.

29. Kerkela R, Grazette L, Yacobi R, lliescu C, Patten R, Beahm C, Walters B, Shevtsov S, Pesant S, Clubb FJ, Rosenzweig A, Salomon RN, Van Etten RA, Alroy J, Durand JB, Force T: Cardiotoxicity of the cancer therapeutic agent imatinib mesylate. Nat Med 2006, 12:908-916.

30. Hatfield A, Owen S, Pilot PR: In reply to 'Cardiotoxicity of the cancer therapeutic agent imatinib mesylate'. Nat Med 2007, 13:13-16.

31. Atallah E, Durand JB, Kantarjian H, Cortes J: Congestive heart failure is a rare event in patients receiving imatinib therapy. Blood 2007, 110:1233-1237.

32. Breccia M, Cannella L, Frustaci A, Stefanizzi C, Levi A, Alimena G: Cardiac events in imatinib mesylate-treated chronic myeloid leukemia patients: A single institution experience. Leuk Res 2008, 32:835-836.

33. Bristol-Myers Squibb: SPRYCEL ${ }^{\circledR}$ prescribing information (US), revised October 2010

34. Novartis: Tasigna (nilotinib) US prescribing information, revised June 2010

35. Kantarjian H, Giles F, Wunderle L, Bhalla K, O'Brien S, Wassmann B, Tanaka C, Manley P, Rae P, Mietlowski W, Bochinski K, Hochhaus A, Griffin JD, Hoelzer D, Albitar M, Dugan M, Cortes J, Alland L, Ottmann OG: Nilotinib in imatinib-resistant CML and Philadelphia chromosome-positive ALL. N Engl J Med 2006, 354:2542-2551

36. Xu Z, Cang S, Yang T, Liu D: Cardiotoxicity of tyrosine kinase inhibitors in chronic myelogenous leukemia therapy. Hematology Reviews 2009, 1:e4

37. Gambacorti-Passerini C, Kim DW, Kantarjian HM, Brummendorf TH, Dyagil I, Griskevicius L, Malhotra H, Goh YT, Wang JY, Gogat K, Cortes J: An Ongoing Phase 3 Study of Bosutinib (SKI-606) Versus Imatinib In Patients with Newly Diagnosed Chronic Phase Chronic Myeloid Leukemia. Blood 2010, 116(Suppl)

38. Quintas-Cardama A, Kantarjian H, Ravandi F, O'Brien S, Thomas D, VidalSenmache G, Wierda W, Kornblau S, Cortes J: Bleeding diathesis in patients with chronic myelogenous leukemia receiving dasatinib therapy. Cancer 2009, 115:2482-2490

39. Gratacap MP, Martin V, Valera MC, Allart S, Garcia C, Sie P, Recher C, Payrastre B: The new tyrosine-kinase inhibitor and anticancer drug dasatinib reversibly affects platelet activation in vitro and in vivo. Blood 2009, 114:1884-1892 
40. Kantarjian H, Shah NP, Hochhaus A, Cortes JE, Shah S, Ayala M, Moiraghi B, Bradley-Garelik M, Zhu C, Baccarani M: Dasatinib compared to imatinib in patients with newly diagnosed chronic-phase chronic myelogenous leukemia in chronic phase: Twelve-month efficacy and safety from the phase III DASISION study. J Clin Oncol 2010, 28(suppl)

41. Bosma PJ, Chowdhury JR, Bakker C, Gantla S, de BA, Oostra BA, Lindhout D, Tytgat GN, Jansen PL, Oude Elferink RP: The genetic basis of the reduced expression of bilirubin UDP-glucuronosyltransferase 1 in Gilbert's syndrome. N Engl J Med 1995, 333:1171-1175

42. Monaghan G, Ryan M, Seddon R, Hume R, Burchell B: Genetic variation in bilirubin UPD-glucuronosyltransferase gene promoter and Gilbert's syndrome. Lancet 1996, 347:578-581

43. Singer JB, Shou Y, Giles F, Kantarjian HM, Hsu Y, Robeva AS, Rae P, Weitzman A, Meyer JM, Dugan M, Ottmann OG: UGT1A1 promoter polymorphism increases risk of nilotinib-induced hyperbilirubinemia. Leukemia 2007, 21:2311-2315

44. Cortes JE, Kantarjian HM, Brummendorf TH, Khoury HJ, Kim DW, Turkina A, Volkert A, Wang J, Arkin S, Gambacorti-Passerini C: Safety and efficacy of bosutinib (SKI-606) in patients (pts) with chronic phase (CP) chronic myeloid leukemia (CML) following resistance or intolerance to imatinib (IM). J Clin Oncol 2010, 28(Suppl)

45. Soverini S, Colarossi S, Gnani A, Castagnetti F, Rosti G, Bosi C, Paolini S, Rondoni M, Piccaluga PP, Palandri F, Giannoulia P, Marzocchi G, Luatti S, Testoni N, lacobucci I, Cilloni D, Saglio G, Baccarani M, Martinelli G: Resistance to dasatinib in Philadelphia-positive leukemia patients and the presence or the selection of mutations at residues 315 and 317 in the BCR-ABL kinase domain. Haematologica 2007, 92:401-404

46. Soverini S, Baccarani M, lacobucci I, Martinelli G: Resistance to tyrosine kinase inhibitors in Philadelphia chromosome-positive leukemias: which mutations matter? Clin Leukemia 2008, 1:223-228

47. Khorashad JS, de LH, Apperley JF, Milojkovic D, Reid AG, Bua M, Szydlo R, Olavarria E, Kaeda J, Goldman JM, Marin D: Finding of kinase domain mutations in patients with chronic phase chronic myeloid leukemia responding to imatinib may identify those at high risk of disease progression. J Clin Oncol 2008, 26:4806-4813

48. Nicolini FE, Corm S, Le QH, Sorel N, Hayette S, Bories D, Leguay T, Roy L, Giraudier S, Tulliez M, Facon T, Mahon FX, Cayuela JM, Rousselot P, Michallet M, Preudhomme C, Guilhot F, Roche-Lestienne C: Mutation status and clinical outcome of 89 imatinib mesylate-resistant chronic myelogenous leukemia patients: a retrospective analysis from the French intergroup of CML (Fi(varphi)-LMC GROUP). Leukemia 2006, 20:1061-1066

49. Bradeen HA, Eide CA, Johnson KJ, Willis SG, Lee FY, Druker BJ, Deininger MW: Comparison of imatinib mesylate, dasatinib (BMS354825), and nilotinib (AMN107) in an N-ethyl-N-nitrosourea (ENU)based mutagenesis screen: high efficacy of drug combinations. Blood 2006, 108:2332-2338

50. Jabbour E, Kantarjian H, Jones D, Breeden M, Garcia-Manero G, O'Brien S, Ravandi F, Borthakur G, Cortes J: Characteristics and outcomes of patients with chronic myeloid leukemia and T315I mutation following failure of imatinib mesylate therapy. Blood 2008, 112:53-55

51. Nicolini FE, Hayette S, Corm S, Bachy E, Bories D, Tulliez M, Guilhot F, Legros L, Maloisel F, Kiladjian JJ, Mahon FX, Le QH, Michallet M, RocheLestienne C, Preudhomme C: Clinical outcome of 27 imatinib mesylateresistant chronic myelogenous leukemia patients harboring a T315I BCRABL mutation. Haematologica 2007, 92:1238-1241

52. Giles FJ, Cortes J, Jones D, Bergstrom D, Kantarjian H, Freedman SJ: MK0457, a novel kinase inhibitor, is active in patients with chronic myeloid leukemia or acute lymphocytic leukemia with the T315I BCR-ABL mutation. Blood 2007, 109:500-502

53. Cortes J, Paquette R, Talpaz M, Pinilla J, Asatiani E, Wetzler M, Lipton JH, Kasap C, Bui LA, Clary DO, Shah N: Preliminary clinical activity in a phase I trial of the BCR-ABL/IGF-1R/aurora kinase inhibitor XL228 in patients with $\mathrm{Ph}+$ leukemias with either failure to multiple TKI therapies or with T315I mutation. Blood 2008, 112(Suppl)

54. Shah P, Asatiani E, Cortes J, Paquette RL, Pinilla-lbarz J, Kasap C, Bui LA, Yaron Y, Clary DO, Talpaz M: Interim results from a phase I clinical trial of the BCR-ABL inhibitor XL228 in drug-resistant Ph+ leukemias. Haematologica 2008, 93(s1):47-48

55. Paquette RL, Shah NP, Sawyers CL, Martinelli G, John N, Chalukya M, Rocchetti M, Fiocchi C, Comis S, Capolongo L, Laffranchi B: PHA-739358, an
Aurora Kinase Inhibitor, Induces Clinical Responses in Chronic Myeloid Leukemia Harboring T315I Mutations of BCR-ABL. Blood 2007, 110(Suppl)

56. Gontarewicz A, Brummendorf TH: Danusertib (formerly PHA-739358)-a novel combined pan-Aurora kinases and third generation Bcr-Abl tyrosine kinase inhibitor. Recent Results Cancer Res 2010, 184:199-214

57. Gontarewicz A, Balabanov S, Keller G, Colombo R, Graziano A, Pesenti E, Benten D, Bokemeyer C, Fiedler W, Moll J, Brummendorf TH: Simultaneous targeting of Aurora kinases and Bcr-Abl kinase by the small molecule inhibitor PHA-739358 is effective against imatinib-resistant BCR-ABL mutations including T315I. Blood 2008, 111:4355-4364

58. O'hare T, Shakespeare WC, Zhu X, Eide CA, Rivera VM, Wang F, Adrian LT, Zhou T, Huang WS, Xu Q, Metcalf CA, Tyner JW, Loriaux MM, Corbin AS, Wardwell S, Ning Y, Keats JA, Wang Y, Sundaramoorthi R, Thomas M, Zhou D, Snodgrass J, Commodore L, Sawyer TK, Dalgarno DC, Deininger MW, Druker BJ, Clackson T: AP24534, a pan-BCR-ABL inhibitor for chronic myeloid leukemia, potently inhibits the T315I mutant and overcomes mutation-based resistance. Cancer Cell 2009, 16:401-412

59. Cortes J, Talpaz M, Deininger M, Shah N, Flinn IW, Mauro MJ, O'Hare T, Spinos N, Hu S, Berk L, Narasimhan N, Rivera VM, Clackson T, Haluska F, Kantarjian HM: A phase 1 trial of oral AP24534 in patients with refractory chronic myeloid leukemia and other hematologic malignancies: first results of safety and clinical activity against $\mathrm{T} 315 \mathrm{I}$ and resistant mutations. Blood 2009, 114(Suppl):267

60. Rivera VM, Xu Q, Wang F, Snodgrass J, O'Hare T, Corbin AS, Keats J, Lamore S, Ning Y, Wardwell S, Russian K, Broudy M, Shakespeare WC, Druker BJ, luliucci JD, Clackson T: Potent Antitumor Activity of AP24534, an Orally Active Inhibitor of Bcr-Abl Variants Including T315I, in In Vitro and In Vivo Models of Chronic Myeloid Leukemia (CML). Blood 2007, 110(Suppl)

61. Van Etten RA, Chan WW, Zaleskas VM, Evangelista P, Lazarides K, Peng C, Li S, Wise SC, Petillo P, Flynn DL: DCC-2036: A Novel Switch Pocket Inhibitor of ABL Tyrosine Kinase with Therapeutic Efficacy Against BCRABL T315I In Vitro and in a CML Mouse Model. Blood 2007, 110(Suppl)

62. Van Etten RA, Chan WW, Zaleskas VM, Walz C, Evangelista P, Lazarides K, Betancur M, Wise S, Petillo PA, Flynn DL: Switch Pocket Inhibitors of the ABL Tyrosine Kinase: Distinct Kinome Inhibition Profiles and in Vivo Efficacy in Mouse Models of CML and B-Lymphoblastic Leukemia Induced by BCR-ABL T315I. Blood 2008, 112(Suppl)

63. Chen Y, Hu Y, Michaels S, Segal D, Brown D, Li S: Inhibitory effects of omacetaxine on leukemic stem cells and BCR-ABL-induced chronic myeloid leukemia and acute lymphoblastic leukemia in mice. Leukemia 2009, 23:1446-1454

64. Quintas-Cardama A, Cortes J: Omacetaxine mepesuccinate-a semisynthetic formulation of the natural antitumoral alkaloid homoharringtonine, for chronic myelocytic leukemia and other myeloid malignancies. IDrugs 2008, 11:356-372

65. Chen Y, Peng C, Sullivan C, Li D, Li S: Novel therapeutic agents against cancer stem cells of chronic myeloid leukemia. Anticancer Agents Med Chem 2010, 10:111-115

66. Cortes JE, Khoury HJ, Corm S, Nicolini F, Schenk T, Jones D, Hochhaus A, Craig AR, Humphriss E, Kantarjian H, Study Group: Subcutaneous omacetaxine mepesuccinate in imatinib-resistant chronic myeloid leukemia patients with the T315I mutation: data from an ongoing phase II/III trial. J Clin Oncol 2009, 27(Suppl)

doi:10.1186/1756-8722-3-47

Cite this article as: Wei et al:: First-line treatment for chronic myeloid leukemia: dasatinib, nilotinib, or imatinib. Journal of Hematology \& Oncology 2010 3:47. 